\title{
Effect of Dietary Supplementation of Marigold Pigment on Immunity, Skin and Meat Color, and Growth Performance of Broiler Chickens
}

\section{author(s)}

N Rajput ${ }^{1}$

M Naeem $^{1}$

$\mathrm{SAli}{ }^{2}$

Y Rui ${ }^{1}$

W Tian ${ }^{1+}$

${ }^{1}$ College of Animal Science \& Technology, ${ }^{2}$ Key Laboratory of Meat Processing and Quality Control, College of Food Science \& Technology, Nanjing Agricultural University, Nanjing 210095, China

\section{-Mail Adress}

*Mail Adress (Corresponding author): College of Animal Science \& Technology, Nanjing Agricultural University, Nanjing 210095, China

email: tianwangnjau@163.com

\section{-Keywords}

Antibody titer, broiler performance, marigold extract, pigmentation.

\begin{abstract}
Marigold flower extract, a natural pigment, was used to determine its effect on carcass and skin pigmentation, immunity and growth performance of broiler chickens. Two hundred and forty 1-day-old Arbor Acres broiler chicks were randomly distributed into four treatment groups with six replicates in a randomized block design. Birds were fed basal diet for $42 \mathrm{~d}$ with or without supplementation of marigold flower extract at various concentrations, i.e., 0 (MG0, control), 100 (MG100), 150 (MG150) and 200 (MG200) mg/kg of feed, respectively. Feed intake and live body weight were weekly recorded. Carcass and shank color, and antibody titers against Newcastle and Influenza viruses were measured. Results showed that marigold flower extract significantly $(p<0.05)$ improved live body weight and relative thymus weight. However, feed intake, feed conversion ratio (FCR), and spleen and bursa weights were not significantly affected. Yellowness $\left(b^{*}\right)$ of breast and thigh muscles increased by the dietary supplementation of marigold flower extract compared with the control diet. However, lightness $\left(L^{*}\right)$, redness $\left(a^{*}\right)$ and redness to yellowness ratio $(a / b)$ were not influenced by the treatments. Moreover, Roche color fan scores of the shank skin were increased at market age ( $d 42)$. The results revealed that marigold extract enhanced antibody titers against Newcastle and influenza viruses. It was possible to conclude that the dietary supplementation with marigold flower extract at the rate of $200 \mathrm{mg} / \mathrm{kg}$ of feed enhanced carcass and shank color, antibody titers against ND and $\mathrm{Al}$, and growth performance of broiler chickens.
\end{abstract}

\section{INTRODUCTION}

It is observed that skin and meat color affect consumers' final judgment of the quality and value of poultry products in China as well as in some other countries (Liang et al., 2004). Pigmentation plays a key role in attracting and convincing consumers, and it is also an important factor in the perception of chicken quality in many countries of the world. Most consumers demand a yellow bird, because this is perceived as indication of health (Sunde, 1992). Corn has the ability of pigmenting poultry products, but its production is limited in many countries, which therefore need to use only rice and wheat in feed formulation. However, these products usually do not produce the desirable yellow color in eggs or poultry meat (Saha et al., 1998).

A number of research studies specified that the main compound with coloring function in meat and eggs are the carotenoids (Blanch \& Hernandez, 2000). Carotenoids are essential for the immune system, have antioxidant effect and cannot be synthesized by poultry that therefore need to obtain these compounds from the diet (Breithaupt, 2007; Jung et al. 2012). Several synthetic pigments are added to 
poultry feeds in China to produce the desirable yellow color, but they are very expensive. On the other hand, natural pigments are less expensive, and may also be beneficial to human health (Zhu et al., 2009).

In order to obtain deeper yolk and skin color, many natural pigments, such as corn gluten meal, curcumin and dehydrated alfalfa meal are used in poultry feeds (Castaneda et al., 2005). Among the aforementioned and many other natural products, the most widely accepted natural pigment is marigold (Tagets erecta). As it is a natural product, it is preferred for inclusion in poultry feeds to obtain the desired pigmentation of poultry products.

Marigold extract (lutein) is a xanthophyll that has strong antioxidant ability, and it is commonly used in commercial poultry feeds as an additive (Koutsos et al., 2006). Based on this information, this study was carried out to evaluate the quantity of marigold extract required to obtain desirable skin color and to improve humoral immune response and body weight of broiler chickens.

\section{MATERIALS AND METHODS}

\section{Experimental design and management}

The experiment was conducted to evaluate the effects of marigold flower extract on meat and skin pigmentation, live performance, and immune status of broiler chickens. Two hundred and forty 1-day-old Arbor Acres broiler chicks were kept in one pen during initial three days and received the same pre-starter diet with no marigold extract supplementation. At the end of three days of the adaptation period, broilers were individually weighed and randomly distributed into four treatment groups (average body weight $\pm 6 \mathrm{~g}$ ) with six replicates in a randomized block design. Chicks were kept in battery cages in an environmentally controlled house. Birds were fed a standard commercial ricefishmeal based diets (Table-1) formulated to meet their nutritional requirements. Pre-starter feeds were fed during first three days, followed by starter feeds from 4 to 21 days, and grower diets from 22 to 42 days of age.

The birds were fed the basal diets for 42 days with or with no supplementation of marigold flower extract (lutein) at the levels of zero (MG0, control), 100 (MG100), 150 (MG150), or 200 (MG200) mg/kg of feed, respectively.

The cages were cleaned and properly disinfected to prevent contamination with pathogenic microorganisms. Temperature was maintained at 34 to $36^{\circ} \mathrm{C}$ for the
Table 1 - Ingredients and nutrient composition of the basal diets.

\begin{tabular}{lcc}
\hline Ingredient (\%) & $\begin{array}{c}\text { Starter } \\
(1 \text { to } 21 \mathrm{~d})\end{array}$ & $\begin{array}{c}\text { Grower } \\
(22 \text { to 42 d) }\end{array}$ \\
\hline Rice & 31.6 & 40.0 \\
\hline Corn & 10.0 & 10.0 \\
\hline Rice polish & 15.0 & 16.0 \\
\hline Fishmeal & 8.5 & 8.0 \\
\hline Soybean & 7.0 & 5.5 \\
\hline Guar meal & 5.0 & 4.0 \\
\hline Canola meal & 11.5 & 8.0 \\
\hline Rapeseed meal & 3.3 & 3.0 \\
\hline Sunflower & 7.0 & 4.4 \\
\hline Limestone & 1.1 & 1.1 \\
\hline Chemical composition & & \\
\hline Crude protein (\%) & 21 & 19 \\
\hline Metabolizable energy (Kcal/kg) & 2800 & 2950 \\
\hline Lysine (\%) & 1.05 & 0.97 \\
\hline Methionine (\%) & 0.4 & 0.38 \\
\hline Methionine + Cystine (\%) & 0.68 & 0.60 \\
\hline Ca (\%) & 1.05 & 0.98 \\
\hline Available P (\%) & 0.49 & 0.46 \\
\hline
\end{tabular}

Mineral premix supplemented $5 \mathrm{~g}$ per kilogram of diet: transretinyl acetate, $25 \mathrm{mg}$; cholecalciferol, $6 \mathrm{mg}$; menadione, $1.2 \mathrm{mg}$; thiamine, $2.3 \mathrm{mg}$; riboflavin, $8 \mathrm{mg}$; nicotinamide, $42 \mathrm{mg}$; choline chloride, $400 \mathrm{mg}$; calcium pantothenate, $10 \mathrm{mg}$; pyridoxine HCl, 4 mg; biotin, 0.04 mg; folic acid, 1 mg; Cobalamin, 0.012 mg; Fe (from ferrous sulfate), 82 mg; Cu (from copper sulfate), $7.5 \mathrm{mg}$; Mn (from manganese sulfate), 110 mg; Zn (from zinc oxide), 64 mg; I (from calcium iodate), 1.1 mg; Se (from sodium selenite), $0.28 \mathrm{mg}$.

first two weeks using an electric brooder, and then gradually reduced up to room temperature. All the birds were allowed to ad-libitum access to feed and water. Feed intake and body weight were weekly recorded and cumulative feed: gain ratios were calculated. At 21 and $42 \mathrm{~d}$ of age, one bird per replicate was randomly selected, weighed, and sacrificed by bleeding, de-feathered and eviscerated. The spleen, bursa and thymus were weighed to calculate their weight relative to live weight according to the formula: (Organ weight /live body weight) $\times 100$.

\section{Color evaluation}

On day 42, three broilers per replicate were randomly selected for shank skin, and breast and thigh meat color evaluation. The intensity of shank skin color was evaluated using Roche color fan. Breast and thigh meat color was evaluated for L* (lightness), 
$a *$ (redness) and b* (yellowness) 45 min after air exposure to allow blooming, using Konica Minolta, chromometer CR-400, (Japan).

\section{Immune response}

All birds were vaccinated against Newcastle disease and avian influenza at 10 days of age, and revaccinated against Newcastle disease via drinking water at 21 days of age. Blood samples were collected from two birds per replicate via wing vein at 20 and 30 days of age to determine antibody titers against to Newcastle disease and avian influenza. Blood samples were centrifuged at $250 \times \mathrm{g}$ for $15 \mathrm{~min}$ at $4 \mathrm{OC}$ to obtain the serum, which was stored at $-20^{\circ} \mathrm{C}$ for further analysis. Antibody titers were determined by using hemagglutination inhibition assay at both ages.

\section{Data analysis}

Data were analyzed by one-way analysis of variance (ANOVA, SAS 9.0, SAS Institute Inc., Cary, NC) and presented as mean \pm standard deviation (SD). Means were compared by the test of Tukey at $p<0.05$ significance level.

\section{RESULTS AND DISCUSSION}

\section{Performance traits}

Feed intake and feed conversion ratio (FCR) were not influenced by dietary marigold extract supplementation ( $p>0.05)$. The highest feed intake (4.33 kg) and best FCR (1.77) were numerically recorded in the MG200 group, despite the lack of statistical difference (Table 2). Similarly, Hasin et al. (2006) showed that feed intake of pullets was not affected with the addition of $4 \%$ marigold in the feed, possibly because it did not feed palatability. On the other hand, Sirri et al. (2007) reported significant enhancement of feed conversion in broilers supplemented with marigold extract.

Live body weight $(2.44 \mathrm{~kg})$ was higher (linear effect, $p<0.05$; quadratic effect, $p>0.05$ ) in MG200 group as compared to the control and other groups. Moreover, Castaneda et al. (2005) showed that higher body weight was recorded in birds fed natural pigment compared with those fed with synthetic pigment. The significant
Table 2 - Effect of marigold flower extract on feed intake, feed conversion ratio (FCR) and live body weight of broiler chickens.

\begin{tabular}{lccccccc}
\hline \multirow{2}{*}{ Items } & \multicolumn{7}{c}{ Dietary Treatment1 } \\
\cline { 2 - 8 } & $\mathrm{C}$ & MG1 & MG2 & MG3 & SEM & L & Q \\
\hline 0-21 d & & & & & & & \\
\hline Feed intake & 1.13 & 1.14 & 1.16 & 1.11 & 8.245 & 0.813 & 0.163 \\
\hline Live body weigh & 0.72 & 0.74 & 0.74 & 0.71 & 6.903 & 0.964 & 0.435 \\
\hline FCR3 & 1.57 & 1.55 & 1.56 & 1.56 & 0.017 & 0.899 & 0.736 \\
\hline 0-42 & & & & & & & \\
\hline Feed intake & 4.26 & 4.23 & 4.30 & 4.33 & 15.648 & 0.086 & 0.101 \\
\hline Live body weigh & $2.35 b$ & $2.37 b$ & $2.40 a b$ & $2.44 a$ & 12.284 & 0.002 & 0.146 \\
\hline FCR3 & 1.81 & 1.79 & 1.79 & 1.77 & 0.010 & 0.174 & 0.999 \\
\hline
\end{tabular}

${ }^{1}$ Control = 0 mg marigold $/ \mathrm{kg}$ feed; MG1 = $100 \mathrm{mg}$ marigold $/ \mathrm{kg}$ feed; MG2 = $150 \mathrm{mg}$ marigold $/$ $\mathrm{kg}$ feed; $M G 3=200 \mathrm{mg}$ marigold $/ \mathrm{kg}$ feed.

${ }^{2} \mathrm{~L}, \mathrm{Q}=$ Linear and quadratic responses to marigold, respectively.

${ }^{3} \mathrm{FCR}=$ feed conversion ratio

abc Values in the same row with no common superscript differ significantly $(P<0.05)$ increase in growth may be due to optimum antioxidant efficiency of marigold extract (lutein), as mentioned by Shanmugasundaram \& Selvaraj (2011), who reported that dietary lutein supplementation increased turkey production by decreasing inflammatory parameters and improving oxidative status.

\section{Immune organs}

Marigold extract supplementation did not show any significant effect on relative spleen and bursa

Table 3 - Effect of marigold flower extract on immune organ weights of broiler chickens

\begin{tabular}{|c|c|c|c|c|c|c|c|}
\hline \multirow{2}{*}{ Items } & \multicolumn{4}{|c|}{ Dietary Treatment ${ }^{1}$} & \multirow[b]{2}{*}{ SEM } & \multicolumn{2}{|c|}{ Effect $^{2}$} \\
\hline & C & MG1 & MG2 & MG3 & & L & Q \\
\hline \multicolumn{8}{|l|}{$21 d$} \\
\hline Spleen & 0.091 & 0.088 & 0.095 & 0.098 & 0.0043 & 0.581 & 0.599 \\
\hline Bursa & 0.290 & 0.291 & 0.308 & 0.360 & 0.0215 & 0.757 & 0.472 \\
\hline Thymus & 0.325 & 0.385 & 0.381 & 0.413 & 0.0152 & 0.048 & 0.810 \\
\hline \multicolumn{8}{|l|}{$42 d$} \\
\hline Spleen & 0.155 & 0.158 & 0.171 & 0.165 & 0.0057 & 0.421 & 0.877 \\
\hline Bursa & 0.236 & 0.247 & 0.283 & 0.295 & 0.0124 & 0.076 & 0.644 \\
\hline Thymus & $0.381^{b}$ & $0.388^{b}$ & $0.496^{a}$ & $0.450^{a b}$ & 0.0157 & 0.016 & 0.915 \\
\hline \multicolumn{8}{|c|}{ 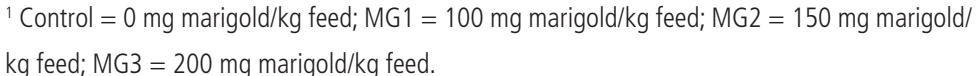 } \\
\hline
\end{tabular}


weights during the starter and finisher periods. However, relative thymus weight increased (linear effect, $p<0.05$; quadratic effect, $p>0.05$ ) in marigold extract supplemented group as compared to control group. On the other hand, Toyomizu et al. (2001) reported that the supplementation of zeaxanthin, another natural pigment, had no significant effect on organ weight. In addition, Elizabeth et al. (2006) demonstrated that LPS-induced lutein-supplemented birds had lower thymus, bursa, and spleen relative weights as compared to control birds, which may indicate that non-supplemented birds suffered severe systemic inflammatory response and that lutein may have reduced the inflammatory response in those fed the supplemented diet.

\section{Shank skin and meat color}

All levels of dietary supplementation of marigold extract produced more intense yellow color in the shank skin compared to the shank skin of non-supplemented broiler (Table 4). Shank skin color intensity was highest in MG200 followed by MG150, MG100, and MG0 (linear effect, $p<0.000$; quadratic effect, $p<0.05$ ). Breast and thigh muscle yellowness $\left(b^{*}\right)$ was significantly higher (linear effect, $p<0.000$; quadratic effect, $p<0.05$ ) in MG200 broilers. Breast and thigh muscle redness $\left(a^{*}\right)$ and lightness $\left(L^{*}\right)$ were not significantly affected by marigold extract supplementation. Castaneda et al. (2005) also reported that natural pigments were more efficient in producing maximum skin yellowness.
In addition, Sirri et al. (2010) measured higher skin yellowness in all body parts of chickens fed 12 to $15 \mathrm{mg}$ xanthophylls per $\mathrm{kg}$ feed, and Ponsano et al. (2004) reported that oxycarotenoids produced by microorganisms enhanced yellowness in the skin and breast and thigh meat of broilers.

\section{Humoral immunity}

The results regarding the effect of dietary supplementation of marigold extract on serum antiNewcastle disease virus (NDV) and Avian Influenza virus (AIV) antibody titers production showed some differences. Antibody titers against Newcastle disease virus were higher in marigold-supplemented groups than the control group (linear effect, $p<0.05$; quadratic effect, $p>0.05$ ) at 20 and 30 days of age. Dietary supplementation of marigold extract failed to produce any effect on antibody titers against AIV on day 20, but it was higher in MG200 group (linear effect, $p<0.05$; quadratic effect, $p>0.05$ ) as compared to controls on day 30 (Table 5). Similarly, Be'de'carrats \& Leeson et al. (2006) reported that carotenoids like lutein also had immunomodulatory potential. Increased dietary pigment enhanced immunocompetence and increased cell-mediated and humoral immune response as compared to controls (McGraw et al., 2003). Our findings are also in agreement with Yuna et al. (2009), who reported that ND titers were significantly higher in marigold-treated layers as compared to control layers.

Table 4 - Effect of marigold flower extract on breast and thigh muscle, and shank color of broiler chickens

\begin{tabular}{|c|c|c|c|c|c|c|c|}
\hline \multirow{2}{*}{ Items } & \multicolumn{4}{|c|}{ Dietary Treatment ${ }^{1}$} & & \multicolumn{2}{|c|}{ Effect $^{2}$} \\
\hline & C & MG1 & MG2 & MG3 & SEM & L & Q \\
\hline \multicolumn{8}{|l|}{ Breast } \\
\hline L* (lightness) & 51.63 & 54.34 & 51.09 & 49.04 & 1.0087 & 0.354 & 0.150 \\
\hline$a^{*}$ (redness) & 8.07 & 8.42 & 8.96 & 8.73 & 0.1818 & 0.130 & 0.713 \\
\hline b* (yellowness) & $9.53^{c}$ & $9.93^{b c}$ & $11.32^{\mathrm{ab}}$ & $12.90^{\mathrm{a}}$ & 0.3896 & 0.000 & 0.027 \\
\hline$a / b$ & 0.366 & 0.373 & 0.251 & 0.283 & 0.0218 & 0.238 & 0.719 \\
\hline \multicolumn{8}{|l|}{ Thigh } \\
\hline L* (lightness) & 46.78 & 46.44 & 49.21 & 48.81 & 0.5232 & 0.49 & 0.315 \\
\hline$a^{*}$ (redness) & 6.24 & 6.35 & 7.32 & 6.52 & 0.3865 & 0.610 & 0.756 \\
\hline b* (yellowness) & $8.55^{c}$ & $9.85^{c}$ & $12,28^{b}$ & $14.09^{a}$ & 0.5772 & 0.000 & 0.012 \\
\hline $\mathrm{a} / \mathrm{b}$ & 0.711 & 0.947 & 0.512 & 0.35 & 0.0898 & 0.097 & 0.089 \\
\hline Shank color & $6.83^{c}$ & $7.07^{\mathrm{bc}}$ & $7.55^{b}$ & $8.64^{\mathrm{a}}$ & 0.1940 & 0.000 & 0.003 \\
\hline
\end{tabular}

${ }^{1}$ Control = $0 \mathrm{mg}$ marigold $/ \mathrm{kg}$ feed; MG1 = $100 \mathrm{mg}$ marigold $/ \mathrm{kg}$ feed; MG2 = $150 \mathrm{mg}$ marigold $/ \mathrm{kg}$ feed; MG3 = $200 \mathrm{mg}$ marigold $/ \mathrm{kg}$ feed.

${ }^{2} \mathrm{~L}, \mathrm{Q}=$ Linear and quadratic responses to marigold, respectively.

abc Values in the same row with no common superscript differ significantly $(p<0.05)$ 
Table 5 - Effect of marigold flower extract on Anti body titers against NDV and AIV of broiler chickens

\begin{tabular}{|c|c|c|c|c|c|c|c|}
\hline \multirow{2}{*}{$\begin{array}{l}\text { Antibody } \\
\text { titer* }(\log 2)\end{array}$} & \multicolumn{4}{|c|}{ Dietary Treatment ${ }^{1}$} & \multicolumn{3}{|c|}{ Effect $^{2}$} \\
\hline & C & MG1 & MG2 & MG3 & SEM & $\mathrm{L}$ & Q \\
\hline \multicolumn{8}{|l|}{$20 d$} \\
\hline ND & $4.72 b$ & $5.01 \mathrm{ab}$ & $4.81 b$ & $6.02 a$ & 0.183 & 0.017 & 0.085 \\
\hline Al & 5.14 & 5.19 & 5.45 & 6.17 & 0.182 & 0.061 & 0.194 \\
\hline \multicolumn{8}{|l|}{$30 \mathrm{~d}$} \\
\hline ND & $5.33 b$ & $5.54 a b$ & $6.21 \mathrm{ab}$ & $6.73 a$ & 0.206 & 0.009 & 0.278 \\
\hline $\mathrm{Al}$ & $6.26 c$ & $6.31 b c$ & $72 a b$ & 7.19a & 0.131 & 0.001 & 0.176 \\
\hline
\end{tabular}

1 Control = $0 \mathrm{mg}$ marigold $/ \mathrm{kg}$ feed; $\mathrm{MG1}=100 \mathrm{mg}$ marigold $/ \mathrm{kg}$ feed; $\mathrm{MG} 2=150 \mathrm{mg}$ marigold $/ \mathrm{kg}$ feed; $\mathrm{MG} 3=200 \mathrm{mg}$ marigold $/ \mathrm{kg}$ feed.

$2 \mathrm{~L}, \mathrm{Q}=$ Linear and quadratic responses to marigold, respectively.

${ }^{*} \mathrm{ND}=$ Newcastle Disease; $\mathrm{Al}=$ Avian Influenza

abc Values in the same row with no common superscript differ significantly $(P<0.05)$

\section{CONCLUSION}

It was concluded that dietary supplementation with marigold flower extract enhanced carcass and shank color, antibodies against ND and Al, and improved growth performance of broiler chickens. Based on the obtained results, it is suggested that marigold extract at the level of $200 \mathrm{mg} / \mathrm{kg}$ diet may be used to enhance humoral antibodies and to improve carcass color and performance of broilers.

\section{REFERENCES}

Be'de'carrats GY, Leeson S. Dietary lutein influences immune response in laying hens. Journal of Applied Poultry Research 2006;15:183-189.

Blanch A, Hernandez JM. Red carotenoids for optimal yolk pigmentation. Feed Mix 2000; 8:9-12.

Breithaupt DE. Modern application of xanthophylls in animal feeding. A review. Trends in Food Science Technology 2007; 18:501-506.

Castaneda MP, Hirschler EM, Sams AR. Skin Pigmentation Evaluation in Broilers Fed Natural and Synthetic Pigments. Poultry Science 2005; 84:143-147.

Elizabeth AK, Garcia Lopez JC, Klasing KC. Carotenoids from in Ovo or dietary sources blunt systemic indices of the inflammatory response in growing chicks (Gallus gallus domesticus). Journal of Nutrition 2006; 136:1027-1031.

Hasin BM, Ferdaus AJM, Islam MA, Uddin MJ, Islam MS. Marigold and orange skin as egg yolk colour promoting agents. International Journal of Poultry Science 2006; 5:979-987.

Jung EK, Clark RM, Park Y, Lee J, Fernandez ML. Lutein decreases oxidative stress and inflammation in liver and eyes of guinea pigs fed a hypercholesterolemic diet. Nutrition Research Practice 2012; 6:113119.
Koutsos EA, Garcia Lopez JC, Klasing KC. Carotenoids from in ovo or dietary sources blunt systemic indices of the inflammatory response in growing chicks (Gallus gallus domesticus). Journal of Nutrition 2006; 136:1027-1031.

Liang YD, Yin JY, Huang BF. Effect of supplemental canthaxanthin and apoester in diets on performance of laying hens and yolk colour. China Poultry 2004; 8:161-163

McGraw KJ, Ardia DR, Carotenoids, immunocompetence, and the information content of sexual colours: an experimental test. American Naturalist 2003; 162:704-12.

Park JS, Chew BP, Wong TS. Dietary lutein absorption from marigold extract is rapid in balb mice. Journal of Nutrition 1998; 128:1802-1806.

Perez-vendrell AM, Hernandez JM, Llaurado L, Schierle J, Brufau J. Influence of source and ratio of xanthophyll pigments on broiler chicken pigmentation and performance. Poultry Science 2001; 80:320-326.

Ponsano EHG, Pinto MF, Garcia Neto M, Lacava PM. Performance and Color of Broilers Fed Diets Containing Rhodocyclus gelatinosus Biomass. Brazilian Journal of Poultry Science 2004; 6:237-242.

Saha PK, Chowdhury SD, Das SC, Saha SK. Replacement value of two Bangladeshi varieties of yellow corn for wheat in the diet of laying chicken. Asian-Australian Journal of Animal Science 1998; 12:776-782.

Shanmugasundaram R, Selvaraj RK. Lutein supplementation alters inflammatory cytokine production and antioxidant status in F-line turkeys. Poultry Science 2011; 90:971-976.

Sirri FN, laffaldano, Minelli G, Meluzzi A, Rosato MP, Franchini A. Comparative pigmentation efficiency of high dietary levels of apo-ester and marigold extract on quality traits of whole liquid egg of two strains of laying hens. Journal of Applied Poultry Research 2007; 16:429-437.

Sirri FN, Petracci MB, Meluzzi A. Survey of skin pigmentation of yellowskinned broiler chickens. Poultry Science 2010; 89:1556-1561.

Sunde ML. The scientific way to pigment poultry products. Poultry Science 1992; 71: 709-710.

Toyomizu M, Sato K, Taroda H, Kato T, Akiba Y. Effects of dietary spirulina on meat colour in muscle of broiler chickens. British Poultry Science 2001; 42:197-202.

Yuna NA, Zang S, Zhang Z, Xi Y, Li Q, Wang J. Effects of marigold extract and $V E$ on anti-oxidation capability and immune response of layers. China Poultry 2009; 31:21-24.

Zhu NH, Zhang RJ, Wu H, Zhang B. Effects of Lactobacillus cultures on growth performance, xanthophyll deposition, and colour of the meat and skin of broilers. Journal of Applied Poultry Research 2009; 18:570578. 